NOTICE: This is the Accepted Version of the following article: Méndez Ardoy, A., Lostalé-Seijo, I., \& Montenegro, J. (2018). Where in the cell is our cargo? Current methods to study intracellular cytosolic localization. Chembiochem. doi: 10.1002/cbic.201800390

\title{
Where in the cell is our cargo? Current methods to study intracellular cytosolic localization.
}

\author{
Alejandro Méndez-Ardoy, ${ }^{[a]}$ Irene Lostalé-Seijo, ${ }^{[a]}$ Javier Montenegro*[a]
}

\begin{abstract}
The internalization and delivery of active substances into cells is a field of growing interest for chemical biology and therapeutics. As we move from small-molecule based drugs towards bigger cargos, such as antibodies, enzymes, nucleases or nucleic acids, the development of efficient delivery systems becomes critical for their practical application. Different strategies and synthetic carriers have been developed including cationic lipids, gold nanoparticles, polymers, cell-penetrating peptides, protein surface modification, etc. However, all these methodologies still present limitations related to the precise targeting of the different intracellular compartments and, in particular, the difficult access to the cellular cytosol. Additionally, the precise quantification of the cellular uptake of a molecule is not enough to demonstrate delivery and/or functional activity. Therefore, methods to determine the cellular distribution of cargos and carriers are of critical importance to identify the barriers that are blocking the activity. In this mini-review, we survey the different techniques that can be currently used to track and monitor the subcellular localization of the synthetic molecules that we deliver inside cells.
\end{abstract}

\section{Introduction}

The development of the next generation of therapeutics such as proteins, nucleic acids, antibodies or analogues ${ }^{[1-6]}$, has the potential to revolutionize chemical biology and medicine. However, the transport of these large, hydrophilic, and labile biomolecules constitutes a great challenge with respect to traditional small-molecule therapies. The activity of these biomolecules usually requires that they reach the cytosol or the nucleus of the cells to interact with its target. Therefore, these molecules have to cross the plasma, the endosomal and, in some cases, the nuclear membrane. ${ }^{[3,7]}$ Different delivery strategies have been developed, from cationic lipids, to gold nanoparticles, including polymers, cell-penetrating peptides, or protein surface modification. However, for all these diverse materials it is always critical to distinguish between the membrane-associated, the endosome-entrapped and the cytosolic/nuclear-fractions, as knowing where the compound is will allow the identification of the barriers that prevent a successful delivery. In this review, we describe different strategies to study the subcellular localization of different

[a] Dr. A. Méndez-Ardoy, Dr. I. Lostalé-Seijo, Dr. J. Montenegro Centro Singular de Investigación en Química Biolóxica e Materiais Moleculares (CIQUS), Departamento de Química Orgánica. Universidade de Santiago de Compostela 15782 Santiago de Compostela (Spain) E-mail: javier.montenegro@usc.es synthetic molecules with particular emphasis on endosomal entrapment and cytosolic release. We will comment on standard and recent approaches for intracellular $\mathrm{pH}$ tracking with focus on ratiometric probes. Microscopy techniques will be carefully described and we will also include different alternative methods that can be used to track and monitor intracellular localization of exogenous molecules.

\section{Fluorescence microscopy and colocalization probes}

Microscopic examination of the distribution of a fluorescently labelled molecule is one of the most direct and visual methods to determine the intracellular localization of a compound. However, this technique has to be used with caution, as artifacts have led to wrong assumptions about the uptake or distribution of substances. For instance, for many years it was assumed that cell-penetrating peptides entered the cells by directly crossing the cell membrane, but that was revealed as a fixation artifact, that prompted intracellular redistribution of the membrane associated peptides..$^{[8,9]}$ The development of live-cell imaging techniques allowed a better understanding of the intracellular fate of penetrating peptides and other membrane-impermeable molecules. In any case, fluorescence microscopy continues to be a powerful tool for intracellular localization studies, as it can report with spatio-temporal resolution on the precise position and distribution of the internalized probes.

The choice of the fluorophore is of great importance and should be taken with care, as its properties might influence the results of the experiment. The $\mathrm{pH}$ sensitivity of certain fluorophores, like fluorescein, reduces the signal when entrapped in acidic compartments and might lead to severe visual underestimation of the quantity of compound in the lysosome. ${ }^{[10]}$ On the other hand, the self-quenching of fluorophores at high concentrations can mask their accumulation, for instance, in the plasma membrane. However, this issue can be mitigated by mixing different proportions of the labelled and the unlabelled compound. ${ }^{[11]}$ Additionally, the fluorescent label might alter the behavior of the transported cargo, as it has been observed that even for charged and water-soluble fluorophores, strong interactions with lipid membranes can occur ${ }^{[12]}$, something that for some molecules has been solved by in situ labelling using click chemistry. ${ }^{[13]}$ It is also possible that the presence of the fluorescent probe triggers, upon irradiation, the generation of singlet oxygen species that can strongly disrupt membranes, causing photolysis of the endosomes and releasing its contents into the cytosol. ${ }^{[14]}$ Additionally, the selection of fluorophores with minimal spectral overlap with the probe used for colocalization is crucial, as cross-talk (simultaneous excitation of two 
NOTICE: This is the Accepted Version of the following article: Méndez Ardoy, A., Lostalé-Seijo, I., \& Montenegro, J. (2018). Where in the cell is our cargo? Current methods to study intracellular cytosolic localization. Chembiochem. doi: 10.1002/cbic.201800390 (C) 2018 WILEY-VCH Verlag GmbH \& Co. KGaA, Weinheim MINIREVIEW

fluorophores by the fixed excitation wavelength) and bleedthrough (collection of the emission of one fluorophore in another channel) might lead to an overestimation of colocalization. ${ }^{[15]}$ Importantly, in the applications concerning molecular probes, the signal detected is the emission of the fluorophore, which is not an indicator of the cargo structural integrity and/or functionality.

\subsection{Organelle specific probes}

Study of colocalization of fluorescently labelled molecules with cellular structures and organelles can be achieved by using other small fluorescent probes or protein markers specific of intracellular compartments. Many fluorophores for the staining of specific organelles have been developed, and many of them can be easily obtained from commercial sources, as MitoTracker for mitochondria, fluorescently labelled ceramides for Golgi apparatus, or ER-tracker to label the endoplasmic reticulum. In this paper, we will focus in the distinction between endosomal and cytosolic location of macromolecular entities. Readers interested in the particular staining of other organelles with the wide variety of small molecular probes are redirected to the corresponding revisions. ${ }^{[16-21]}$ For the cellular internalization of macromolecular entities and nano-asssemblies, the cargocarrier complexes are typically taken up by endocytosis. The initial stages of this process do not present strong differences in their chemical properties that can be used for efficient chemical differentiation and to the best of our knowledge there are no specific small-molecular probes to label the first stages of the endosomal pathway. However, with a strict control of time, some cell impermeable fluorophores such as Lucifer Yellow, ${ }^{[22]}$ or membrane markers as FM 4-64,[23] have been used to track endocytosis. Additionally, several fluorescently labelled proteins and polymers, such as dextran, are available to follow their internalization pathways. For instance, transferrin is typically used to track clathrin-mediated endocytosis and recycling endosomes ${ }^{[24]}$ while cholera toxin subunit $B$ has been used for caveolin-dependent endocytosis. ${ }^{[24]}$ However, to better identify subsets of endosomes, there are several fluorescent proteins fused to endosomal markers, such as Rab5 and EEA1 for early endosomes, Rab11 for recycling endosomes, or Rab7 for late endosomes ${ }^{[25,26]}$ that can be expressed in cells using plasmids or viruses.

After endocytosis, cargos may end up in lysosomes, an acidified compartment in which molecules are degraded. This difference with cytosolic $\mathrm{pH}$ is exploited by several fluorophores for the specific labelling of the lysosome, as the compounds are usually not charged at neutral $\mathrm{pH}$, and able to diffuse throughout the cell, and accumulate in acidic organelles after protonation. Acridine orange and other cationic dyes were initially employed with this purpose, ${ }^{[27]}$ but better fluorophores with less unspecific staining have been developed. LysoTracker dyes are one of the most popular lysosomal markers, ${ }^{[21]}$ that have a simple staining protocol, in which cells are incubated for $30 \mathrm{~min}$ to $2 \mathrm{~h}$ with a small amount of the fluorophore dissolved in medium. However, prolonged incubation with these probes can modify the $\mathrm{pH}$ of the organelle and a rare event of photoconversion can transiently modify the spectral properties of LysoTracker Red DND-99. In this case, after irradiation part of the molecule looses conjugation and behaves as a green fluorophore. ${ }^{[28]}$ As the accumulation of these probes is dependent on acidification, these markers are not useful for fixed cells or conditions in which the lysosomal $\mathrm{pH}$ is compromised. In that cases, it is recommended to use either fluorophores that react specifically with lysosomal cathepsins ${ }^{[29]}$ or chimeric fluorescent protein markers such as LAMP-1-GFP. ${ }^{[30]}$ In addition to colocalization studies with lysosomes, the use of Golgi specific probes might be of interest to study the possibility of retrograde transport of the compounds. ${ }^{[10]}$

\subsection{Colocalization analysis}

After image acquisition, colocalization analysis should be processes with software, such as Image ${ }^{[31]}$ and its plugins Coloc2 or JACoP. ${ }^{[15]}$ Colocalization parameters frequently used are Pearson's, or Spearman's, correlation coefficients (for linear and non-linear correlations, respectively) and Mander's overlap coefficients. Pearson's and Spearman's coefficients are a measure of the correlation between pixel intensities in the two channels, ${ }^{[15,32]}$ while Mander's coefficients quantify the overlap of the pixels above the background of one channel to the positive pixels in the other channel, regardless their intensity. ${ }^{[15,32]}$ Understanding the advantages and limitations of each metric is essential for data interpretation. ${ }^{[15,32]}$

\section{3. $\mathrm{pH}$ sensitive probes}

As introduced for lysosomal markers, different local $\mathrm{pH}$ environments can be found within different cellular organelles. ${ }^{\text {[3] }}$ When introduced into cellular environments, protonable fluorescent probes can report on local $\mathrm{pH}$ variations near the particular $\mathrm{pK}_{\mathrm{a}}$ of the probe. However, unless the protonation event is particularly sharp, ${ }^{[34]}$ the accurate intracellular $\mathrm{pH}$ quantification is hardly achieved through an "on-off" type response due to aggregation of the fluorophores. This can be avoided by the use of fluorescent probes with different absorption or emission wavelengths for the acidic and basic forms. The signal can thus be expressed as the ratio of the two wavelengths (ratiometric), eliminating the concentration artifacts. A widely used example in this sense is benzo[c]xanthene derivatives, such as the structures shown in Figure 1a. The large differences between the maximum emission wavelength of protonated and unprotonated species is well suited to collect the fluorescent signal using a fluorescence microscope equipped with a suitable filter set-up. Depending on the $\mathrm{pH}$ interval of interest, one has to carefully select a probe that has a large dynamic range in such interval. Therefore, cytosol $\mathrm{pH}$ variations could be measured with unfluorinated benzo[c]xanthene $\left(\mathrm{pK}_{\mathrm{a}}\right.$ 7.5) while fluorinated ${ }^{[35,36]}$ analogues would be more appropriated for endosomal maturation processes $\left(\mathrm{pK}_{\mathrm{a}} \sim 6.4\right)$. Nowadays a variety of ratiometric probes are commercially available (i.e. SNARF ${ }^{\circledR}-4 \mathrm{~F}$ 5-(and-6)-carboxylic acid in Figure 1a) and new examples are reported continuously. ${ }^{[37]}$ Traditional molecular fluorescent probes suffer of several disadvantages, 
NOTICE: This is the Accepted Version of the following article: Méndez Ardoy, A., Lostalé-Seijo, I., \& Montenegro, J. (2018). Where in the cell is our cargo? Current methods to study intracellular cytosolic localization. Chembiochem. doi: 10.1002/cbic.201800390

(C) 2018 WILEY-VCH Verlag GmbH \& Co. KGaA, Weinheim

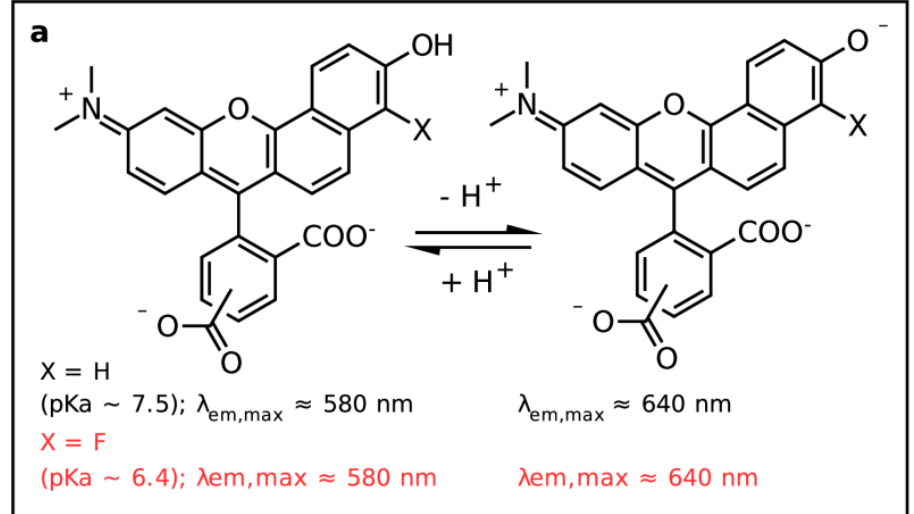

d f $-\mathrm{O}_{3} \mathrm{~S}$

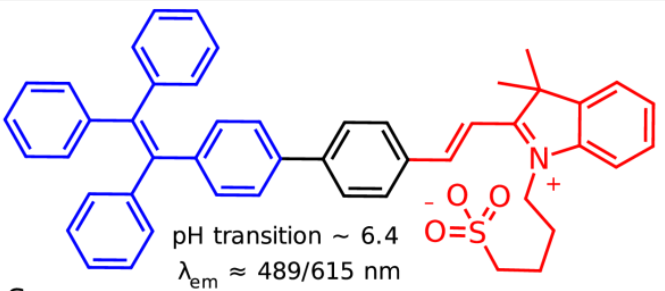
$\lambda_{\mathrm{em}} \approx 489 / 615 \mathrm{~nm}$<smiles>CC[N+]1=C(/C=C/C=C/C=C2\Nc3ccc(CC(=O)O)cc3C2(C)C)C(C)(C)c2cc(C)ccc21</smiles>

b

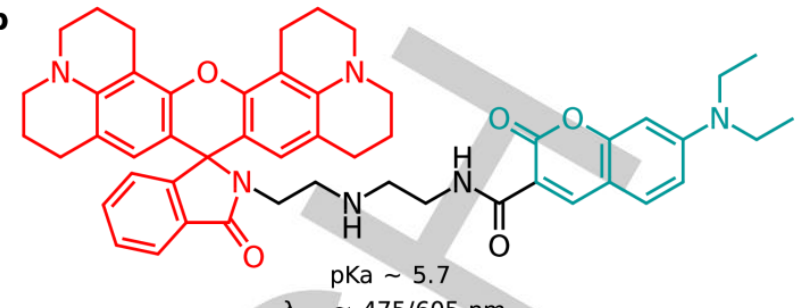

c

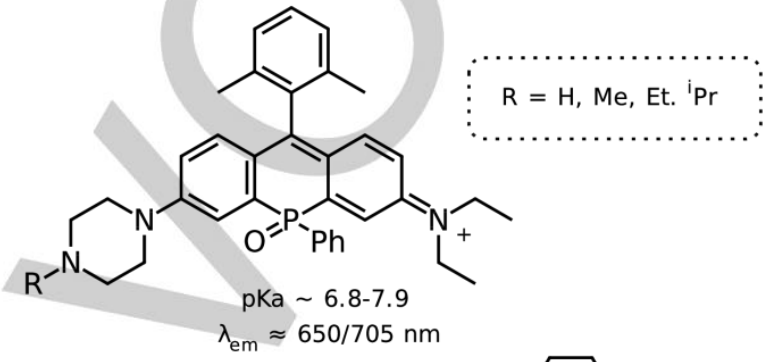

e<smiles>CN(C)CCNC(=O)CN(C)c1ccc2cc(-c3nc4ccccc4[nH]3)ccc2c1</smiles>

Figure 1. Selected examples of fluorescent sensors for ratiometric intracellular $\mathrm{pH}$ measurements. Typical emission wavelengths and $\mathrm{pK} \mathrm{a}_{\mathrm{a}}$ or $\mathrm{pH}$ working range are indicated below: a) Acid-base equilibrium of the archetypical ratiometric probe SNARF (fluorinated and unfluorinated). ${ }^{[6]}$ b) Rhodamine(red moiety)-coumarine (green moiety) hybrid for lysosomal monitoring; c) Asymmetric rhodamine-inspired probes with tunable $\mathrm{pK}_{\mathrm{a}}$; d) Example of AlEgen designed for broad pH ratiometric measurements in cells. Red and blue moieties denote cyanine and AlEgen moieties respectively; e) Benzimidazole-naphtalene conjugate used in twophoton spectroscopy; f) Example of a classical cyanine probe.

including photobleaching or aggregation quenching. More importantly, low tissue penetration strongly hinders the desired tracking of tissues rather than cell monolayers. Therefore, there is a strong interest in the development of molecular or nanoparticle-based $\mathrm{pH}$ probes. ${ }^{[38]}$ We will here highlight some recent examples of molecular probes to shine light into celular $\mathrm{pH}$ alterations, such as the increase of lysosome $\mathrm{pH}$ during a heat shock, ${ }^{[39]}$ the lysosomal acidification during autophagy, and the apoptosis happening after a viral infection. ${ }^{[40]}$

\subsection{Rhodamine-based probes}

Rhodamines have some excellent properties as fluorescent probes, but they don't show $\mathrm{pH}$ dependence at biological relevant $\mathrm{pH}$ values. Several groups have tried to develop $\mathrm{pH}$ sensitive rhodamines and $\mathrm{Han}$ and co-workers ${ }^{[40]}$ have recently reported the integration of rhodamine and coumarine dyes for lysosomal $\mathrm{pH}$ tracking (Figure $1 \mathrm{~b}$ ). The ratiometric response is achieved through acid-mediated intramolecular lactame opening and coumarin fluorescence insensitivity. Lysosomal localization was demonstrated in experiments in HeLa cells expressing Lamp2-GFP showing the overlap of GFP and rhodamine/coumarin signal. Asymmetric rhodamines have been modified by the inclusion of a piperazine ring with different substituents to tune the $\mathrm{pK}_{\mathrm{a}}$, the quantum yield and the wavelength to biologically relevant $\mathrm{pH}$ ranges $\left(\mathrm{pK}_{\mathrm{a}} 5.5\right.$ to 6.7$)$. Oxygen to phosphorous substitution in the xanthane ring allowed in vivo imaging by shifting the fluorescence emission to the near infrared for both protonated and unprotonated species (Figure 1c). ${ }^{[41]}$

\subsection{New induced emissive probes and in vivo probes}

Self-quenching probes suffer from undesired reduction of signal to noise ratio. However, the new aggregation-induced emission (AIE) probes ${ }^{[33]}$ have allowed the development of interference free sensors that can precisely report on $\mathrm{pH}$ variations. The coupling of a cyanine dye (Figure 1d, red moiety) to an AlEgen tetraphenylethylene (Figure 1d, blue moiety) $)^{[43]}$ allowed the intracellular $\mathrm{pH}$ tracking along a $\mathrm{pH}$ range of $5.0-7.4$ by showing the acid and basic cellular micro-environments in red and blue fluorescent emission respectively. Although several aggregation induced emission probes can be found in the literature, ${ }^{[44-47]}$ their "in cellulo" implementation still remains a challenge. For 
NOTICE: This is the Accepted Version of the following article: Méndez Ardoy, A., Lostalé-Seijo, I., \& Montenegro, J. (2018). Where in the cell is our cargo? Current methods to study intracellular cytosolic localization. Chembiochem. doi: 10.1002/cbic.201800390 (C) 2018 WILEY-VCH Verlag GmbH \& Co. KGaA, Weinheim

example, they can interact with lipids which results in changes of their physicochemical properties. ${ }^{[43,47]}$ The emergence of twophoton microscopy ${ }^{[48]}$ and new near infrared (NIR) fluorescent probes have triggered new opportunities to study molecular behavior inside living cells and tissues. ${ }^{[49]}$ A recent example exploits the protonation of the imidazole moiety $\left(\mathrm{pK}_{\mathrm{a}}\right.$ between 4.9-6.1) of a 2-aminonaphthalene-benzimidazole scaffold to turn this molecule into suitable lysosomal $\mathrm{pH}$ tracking probe (Figure 1e). ${ }^{[50]}$ By using this probe, two-photon microscopy $(740-750 \mathrm{~nm}$ excitation) was used to monitor $90-180 \mu \mathrm{m}$ depth tissue of rat fresh hippocampus, revealing differences in the $\mathrm{pH}$ distribution along the hippocampal circuit. To address higher $\mathrm{pH}$ values, the $\pi$-conjugation of naphtol scaffolds can be increased by conjugation to a benzothiazolyl moiety or using benzochromene2-one derivatives. The later was be further functionalized with a triphenyl phosphonium salt in order to target mitochondria. ${ }^{[11]}$ Alternatively, in vivo tracking of intracellular $\mathrm{pH}$ can also be achieved by using near infrared properties of cyanine scaffolds (a classical example is shown in Figure 1f). In this example, the chemical tailoring controls the photophysical properties and the ratiometric reading, which are optimized by minimizing the cross-talk between emission bands. ${ }^{[52]}$

\section{3. pH sensitive probes and cytosolic location}

The labelling of the cargo with $\mathrm{pH}$ sensitive probes can be used to detect their accumulation into the acidic compartments of the cells (i.e. endosomes and lysosomes) or their presence in the cytosol ( $\mathrm{pH} \sim 7.4)$. For instance, estimations of endosomal escape efficiency can be obtained by comparing the fluorescence of a compound labelled with a $\mathrm{pH}$ insensitive probe, as rhodamine, to the signal obtained with a naphthofluorescein label, which presents a pKa of 7.8, and it is only fluorescent at

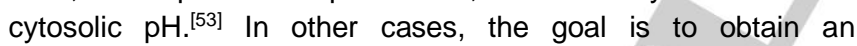
estimation of the $\mathrm{pH}$ value in the environment of the particle, by using ratiometric probes. Before the final measurements in the cells, a pH calibration curve in intracelullar environment is required by incubating cells with buffers at various $\mathrm{pH}$ plus a proton ionophore such as nigericin. This has been used to study the fate of DNA-polyplexes, labelled with SNARF-4F ${ }^{[54]}$ or with Cy5 and fluorescein, ${ }^{[55]}$ and the cytosolic release of polymeric micelles labelled with 7-hydroxycoumarin and tetramethylrhodamine ${ }^{[56]}$. Using a similar strategy, endosomal escape rates for non-viral vehicles labelled with Oregon Green and $\mathrm{pHrodo}$ were calculated by fitting the average $\mathrm{pH}$ at several time points to a first-order mass action kinetic mathematical model of cellular trafficking. ${ }^{[57]}$

\section{Disulfide self-immolative strategies}

The precise tracking and quantification of the cytosolic release of synthetic molecules could be challenging due to difficult fluorescence signal identification and differentiation inside the different cellular compartments (i.e. cytosol versus endosome). Therefore, it is a crucial task to identify orthogonal chemical intracellular environments that can generate a readout signal for probe activation and/or modulation. In this regard, the high concentration of glutathione (1-10 mM) in the cytosol of eukaryotic cells generates a reductive environment that can be exploited to trigger a response in redox-sensitive probes. Disulfide bonds are thus efficiently reduced in the cytosol splitting a dynamic molecular assembly into its individual components (Figure 2a). In a pioneering work, Langel and coworkers employed a quencher/dye couple to easily quantify the kinetics of the cytosolic release of a penetrating peptide vehicle. ${ }^{[58]}$ In this elegant strategy the disulfide was employed to connect a random peptide sequence (LKANL) -with no translocation capabilities- bearing a fluorophore (marker) as model cargo and a penetrating peptide vehicle bearing the corresponding quencher (Figure 2c). Beyond redox sensitive conjugation and release, ${ }^{[59,60]}$ Wender and co-workers have also proposed a very creative solution to quantify in real-time the uptake and cytosolic release of an enzyme substrate cargo. ${ }^{\text {[52-53] }}$ This strategy builds on the inhibition of luciferin self-immolative linker (i.e. carbonates ${ }^{[61]}$ and carbamates ${ }^{[62,63]}$ ) that degrade after disulfide reduction removing the extra pendant group and releasing intact luciferin (Figure $2 b$ ). This strategy relies in the conjugation of luciferin phenol to a cell penetrating peptide via a reactive chloroformate group that includes a redox sensitive disulfide function. The resulting carbonate was relatively stable in aqueous buffer but after disulfide reduction the nucleophilic attack of the newly formed thiol to the carbonyl of the carbonate released intact luciferin and the corresponding cyclic Sthiocarbonates. This approach ensured the cytosolic signal generation by two layers of control: 1) restricted release of luciferin at the cytosol reductive environment and 2) cytosolic confinement of the luciferase enzyme. ${ }^{[61]}$ This new conceptual strategy paved the way to new therapeutic ${ }^{[64]}$ and theranostics strategies as exemplified by camptothecin linked to a piperazinerodol fluorophore by disulfide self-immolative linkers. This strategy allowed simultaneous cytotoxicity dose response treatment and cellular uptake visualization both in cellular studies and in mice models. ${ }^{[65]}$ Hyperbranched pro-drugs amphiphilies tethered with Gd complex were self-assembled into monomolecular micelles to protect the hydrophobic pro-drug (camptothecin) to exposure to the extracellular medium that could potentially promote degradation of the carbonate or carbamate groups. The disulfide degradation caused a hydrophobic-hydrophilic transition of the micelles, which triggered the release of the camptothecin and the increase of the magnetic resonance contrast. ${ }^{[66]}$

Disulfide-based methodologies have been confirmed as excellent assays to precisely track cytosolic release and avoid non-desired noise interference. However, the complexity of the cell environment would sometimes require a careful inspection for reliable quantification, as multiple factors such as potential disulfide exchange or the different reducing potential of different cell lines might affect these measurements in a significant degree. ${ }^{[58,67,68]}$ Interestingly, disulfide self-immolative linkers can be used to obtain quantitative kinetic information of cellular internalization of vectors of interest, such as cell penetrating peptides. ${ }^{[68]}$ On the other hand, when monitoring more complex processes such as cell penetration in complex living organisms, 
NOTICE: This is the Accepted Version of the following article: Méndez Ardoy, A., Lostalé-Seijo, I., \& Montenegro, J. (2018). Where in the cell is our cargo? Current methods to study intracellular cytosolic localization. Chembiochem. doi: 10.1002/cbic.201800390 (C) 2018 WILEY-VCH Verlag GmbH \& Co. KGaA, Weinheim

a

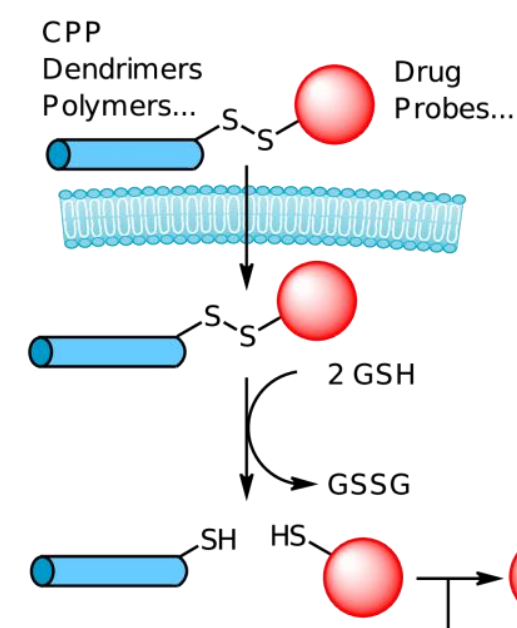

Carbonate

Carbamate

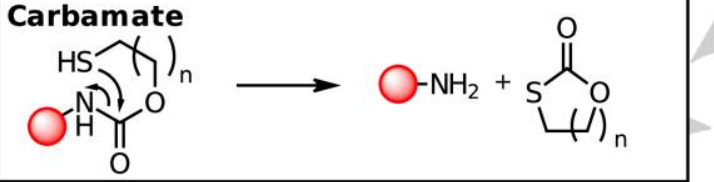

linker immolation<smiles>CCOC(=O)[C+]1CCCO1</smiles>

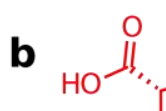

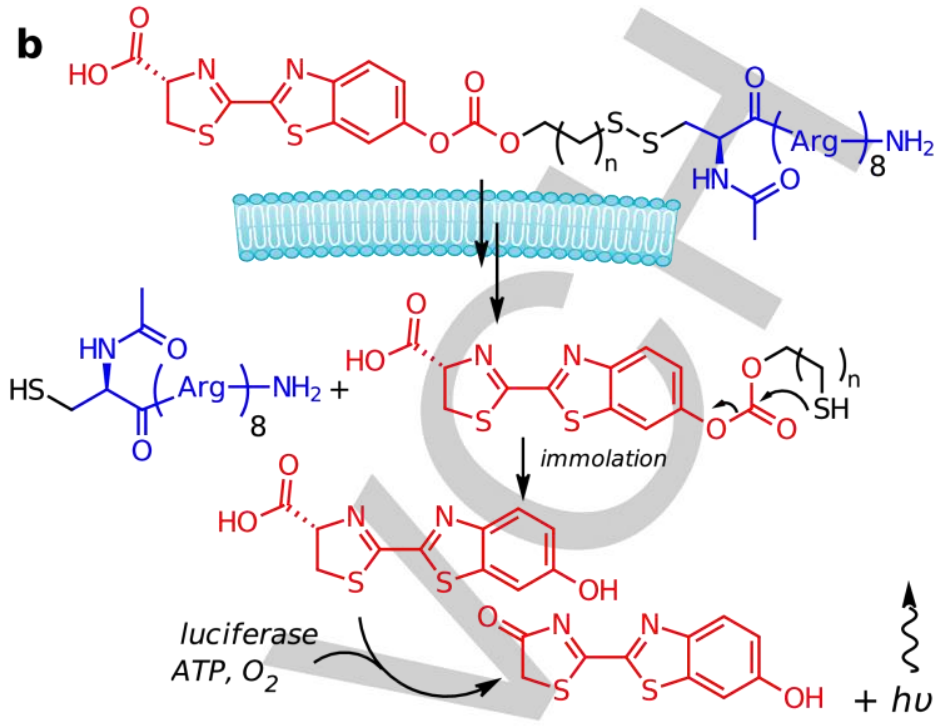

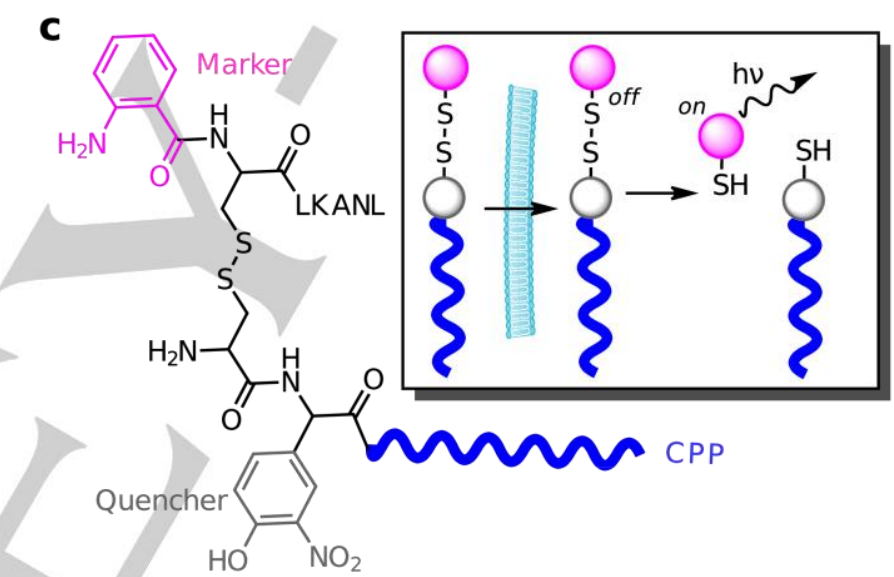

Figure 2. Disulfide self-immolative strategies. a) Scheme of disulfide reduction in the presence of intracellular glutathione concentration in the cytosol; insert shows degradation of carbonate and carbamate linkers triggered by nucleophilic attack of the free thiol; b) Chemiluminescent platform composed of a luciferinoctaarginine hybrid bridged through a self-immolative linker for real time visualization of cellular uptake, where $n=1,2$ or $3 ;$; $^{[61]} \mathrm{c}$ ) Reduction triggered activation of a fluorophore connected with a cell penetrating peptide that bears a fluorescence quencher. The model cargo is constituted by a marker (model fluorophore 2 aminobenzoic acid) and a random peptide sequence LKANL. [58]

the circulation time of disulfides can also be affected by extracellular reductive components such as free protein cysteines. To improve this limitation for in vivo delivery applications, the steric protection of the disulfide bond has been explored. Constrained disulfides were obtained by the modification of the cysteines of engineered antibodies with thiolbearing drugs. These conjugates can be targeted to particular cells and after internalization and antibody degradation, the enhanced accessibility to the disulfide bonds improved drug release rate while preserving an increased in vivo circulation time. ${ }^{[69]}$

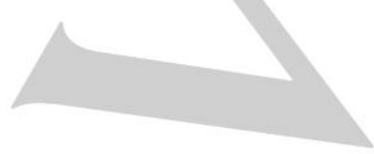

\section{Strategies based in protein activity or protein interactions}

Organelle fluorescent markers and $\mathrm{pH}$-tracking probes can provide useful insights on intracellular localization. However, demonstration of functional activity constitutes the final proof to unambiguously demonstrate that a particular compound has reached its targeted intracellular destination. Ideally, the activity of the final cargo should be directly measured and quantified as an increasing time-resolved signal. For nucleic acids, the expression or silencing of a reporter gene facilitates functional activity validation. However, for the optimization and localization of delivered proteins this is not always the case, as signal detection can be expensive, time consuming and not suitable for 
NOTICE: This is the Accepted Version of the following article: Méndez Ardoy, A., Lostalé-Seijo, I., \& Montenegro, J. (2018). Where in the cell is our cargo? Current methods to study intracellular cytosolic localization. Chembiochem. doi: 10.1002/cbic.201800390 (C) 2018 WILEY-VCH Verlag GmbH \& Co. KGaA, Weinheim

high-throughput screening or routine tests. Therefore, several assays have been devised to establish if a protein or a synthetic cargo has reached the cytosol. Providing the right controls and calibration curves are done, some of these protocols allow quantitative or semi-quantitative estimations of endosomal escape. ${ }^{[70-78]}$

Although simple fluorescent microscopy analysis should be supported with other quantification techniques, it can be useful for the visual tracking and the qualitative assessment of the cytosolic distribution of a protein cargo (Figure 3a). However, to be reliable in this assignment, the distribution of the cytosolic protein has to be clearly different from the membrane associated or the endosomal entrapped signals. To this purpose, it is necessary to use proteins with defined intracellular localizations. This can be achieved by exploiting the intrinsic protein affinity to subcellular structures (i.e. antibodies). Alternatively, proteins can also be modified with targeting tags to redirect them to a new particular intracellular localization (i.e. nucleus), which can only be reached if the protein is delivered at the cytosol of the cell. Some examples include fluorescent proteins or peptides bearing a NLS for nuclear accumulation, ${ }^{[79,80]}$ antibodies specific for cytoskeletal proteins ${ }^{[80,81]}$ or the nuclear membrane ${ }^{[81]}$ and other recognisable structures ${ }^{[82]}$. Accumulation in the nucleoli of some cationic CPPs and their proteins conjugates ${ }^{[83]}$ have also been used as an indicative of endosomal release. Additionally, endosomal leakage can be studied by the use of labelled polymers, such as dextran, or membrane-impermeable dyes such as calcein. ${ }^{[82,84]}$

\subsection{Enzymatic or functional activity}

Demonstration of enzymatic activity constitutes a better proof of the delivery of an intact functional protein cargo. Luciferase fused to $\mathrm{CPPs}^{[85]}$ or bacterial $\beta$-galactosidase ${ }^{[80]}$ have been traditionally used. However, in these examples there is not a clear distinction between the activity of the cytosolic and the endosomal-entrapped proteins. To solve this limitation, proteins that are only active when released into the cytosol or proteins exclusively expressed in the cytosol that give rise to a measurable signal after reacting with the delivered cargo can be used. One of them is Cre recombinase from bacteriophage P1, which mediates DNA recombination between two loxP sites. ${ }^{[86]}$ In mammalian genomes the recombination sequences are absent, allowing the introduction of reporter constructs that conditionally express a fluorescent protein or other reporter gene upon the delivery of the Cre recombinase (Figure $3 b) .{ }^{[86]}$ This method has been used to measure protein delivery using

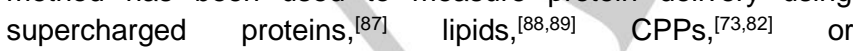
osmocytosis. ${ }^{[90]}$ A chimeric protein of this recombinase fused to an antibody crystallizable fragment ( $\mathrm{Fc}-\mathrm{Cre}$ ), was also explored to test the efficiency of antibody delivery. ${ }^{[11]}$

The bacterial biotin ligase BirA, ${ }^{[92]}$ which specifically biotinylates a short peptide sequence (GLNDIFEAQKIEWHE) can be used to track citosol protein delivery by two different methods. On one hand, the BirA protein can be delivered into cells that express another protein, confined in the cytosol, and bearing the corresponding acceptor peptide. ${ }^{[73]}$ On the other hand, the protein of interest or the carrier can be equipped with the acceptor peptide, which will be biotinylated by a constitutively expressed cytosolic BirA. ${ }^{[93]}$ In both cases, cellular lysis and Western blotting with streptavidin are required for the detection of the biotinylated proteins.

Deubiquitinases are nucleocytoplasmic enzymes that are able to cleave the peptide bond between ubiquitin and other proteins. ${ }^{[94]}$ The reduction of protein size after deubiquitination can be used in this enzymatic assay for the study of the cytosolic delivery of ubiquitin-tagged proteins fused to CPPs, ${ }^{[95]}$ zinc-finger domains, ${ }^{[85]}$ or supercharged proteins. ${ }^{[87]}$

Cytosolic enzymes can also be used to activate fluorogenic labels. The overexpression of bacterial $\beta$-galactosidase in the cell cytosol has been explored to unmask the fluorescence emission of fluorescein di- $\beta$-D-galactopyranoside, in which the fluorophore is quenched by the glycosilation of both hydroxyl groups of the xanthene core. However, to avoid non-specific lysosomal activation and reduce signal background, it is necessary to further modify the cell line by knocking-down (by overexpression of a shRNA) an endogenous lysosomal galactosidase. ${ }^{[75]}$

Another option is the use of toxins or proapoptotic proteins that induce cell death when reaching the cytosol, like Caspase $3,{ }^{[96]}$ cytochrome $\mathrm{C}{ }^{[97]}$ or the plant toxin saporin. ${ }^{\left[{ }^{[82}\right]}$ These toxins enter the cell by an endocytic mechanism but cannot leave efficiently the endosome. As long as they stay in the endosome the cell metabolizes them and they do not show any toxic activity. However, upon incubation with a carrier able to release the intact proteins into the cytosol the viability of the cells will be reduced. By measuring the toxicity in the presence and absence of the carrier, one can compare the efficiency on protein cytosolic release. Controls to account for the toxicity of the carrier itself must also be performed in these experiments.

\subsection{Protein Complementation}

Protein complementation is another method to track for protein delivery in the cell cytosol. In bimolecular fluorescence complementation (BiFC) a fluorescent protein is split in two nonfluorescent fragments. Therefore, the protein will only recover its fluorescence after the intracellular association of the fragments (Figure 3c). ${ }^{[98]}$ One of the most interesting version of split proteins divides GFP in a 10 strands protein and 1 oligopeptide (16 amino acids) as the complementation partner. ${ }^{[99]}$ This technique was applied to confirm cytosol delivery of cellpenetrating peptides, ${ }^{[76]}$ protein-CPP fusions, ${ }^{[77]}$ or antibodies into cells. ${ }^{[70,100]}$ In the latter case, to enhance GFP reconstitution, the antibody-oligopeptide partner and the non-fluorescent GFP110 can be fused to streptavidin binding peptide (SBP2) and streptavidin, respectively. ${ }^{[70]}$

\subsection{Steroid Receptors}

Another set of methods is based on the response of steroid receptors. Upon binding to their ligands, these receptors undergo several conformational changes that trigger their translocation to the cell nucleus. The estrogen receptor can be 
NOTICE: This is the Accepted Version of the following article: Méndez Ardoy, A., Lostalé-Seijo, I., \& Montenegro, J. (2018). Where in the cell is our cargo? Current methods to study intracellular cytosolic localization. Chembiochem. doi: 10.1002/cbic.201800390 (c) 2018 WILEY-VCH Verlag GmbH \& Co. KGaA, Weinheim

expressed in the cell cytosol fused to a cytosolic version of Cre recombinase. The delivered molecule (i.e. small peptide) has to be tagged with the corresponding molecular ligand (tamoxifen or 4-hydroxycyclofen). Therefore, when the ligand-tagged molecule reaches the cytosol, it triggers the Cre nuclear translocation and thus recombines the reporter sequence. ${ }^{[101]} A$ second different method is based in the glucocorticoid receptor (GR) and its ligand dexamethasone. Two different assays have been devised, named GIGI (glucocorticoid induced eGFP induction) and GIGT (glucocorticoid induced eGFP translocation) (Figure $3 d$ ). ${ }^{[78]}$ In the GIGI assay, the ligand-binding domain of the GR is fused to a Gal4 DNA binding domain and VP16 transactivation domain. The Gal4 DNA binding domain allows the recognition of a DNA promoter sequence, while the VP16 transactivation domain recruits transcription factors necessary for RNA pol II activity and transcription. After binding to the dexamethasone, the chimeric protein accumulates into the nucleus and activates the expression of genes under the control of a Gal4 responsive promoter, typically GFP ${ }^{[78]}$ or luciferase. ${ }^{[102]}$ Alternatively, in the GIGT assay, the ligand-binding domain of the glucocorticoid receptor is fused to the green fluorescent protein. After dexamethasone binding, the nuclear accumulation of the fluorescent chimera can be measured from microscopy images of living cells using image analysis software as CellProfiler and expressed as a translocation ratio (nuclear over cytosolic fluorescence). ${ }^{[6,78,103,104]}$ Interestingly, the possibility of performing these nuclear translocation experiments in the presence of some endocytic inhibitors can be applied to assign

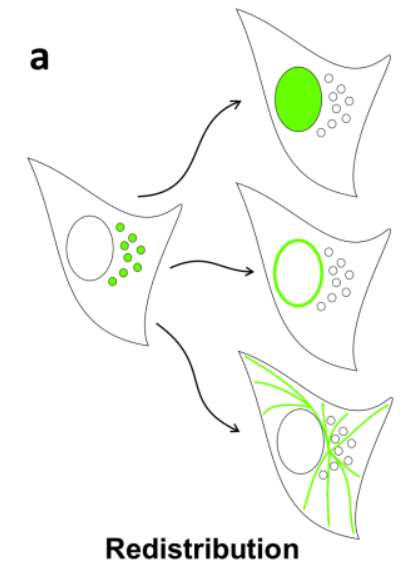

b

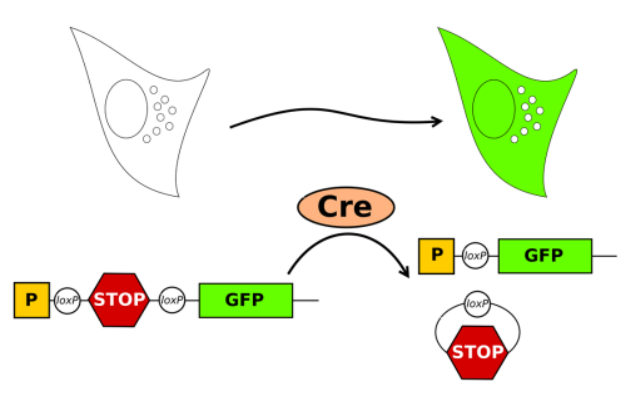

Cre recombinase
C

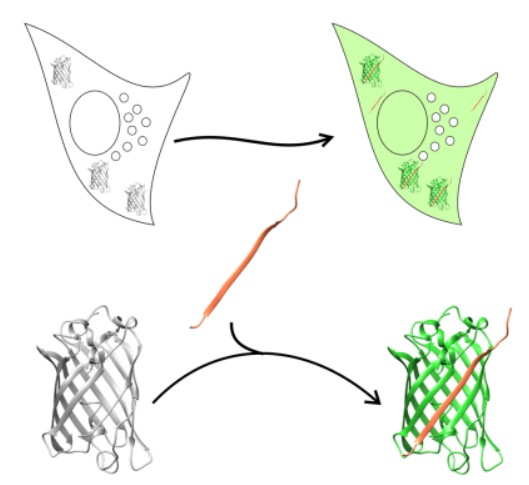

BiFC d

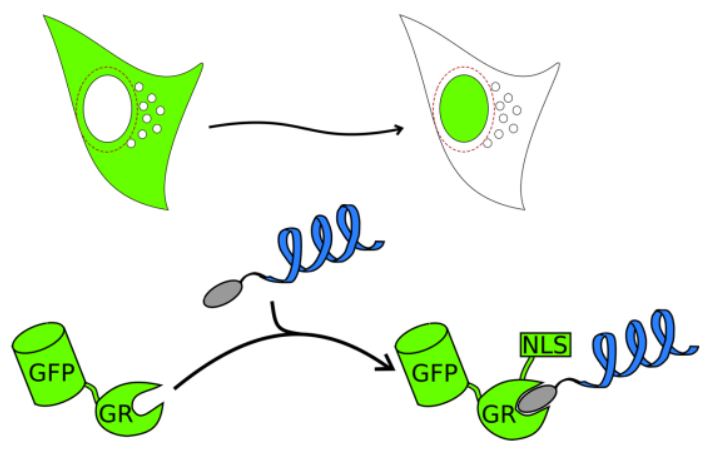

GIGT e

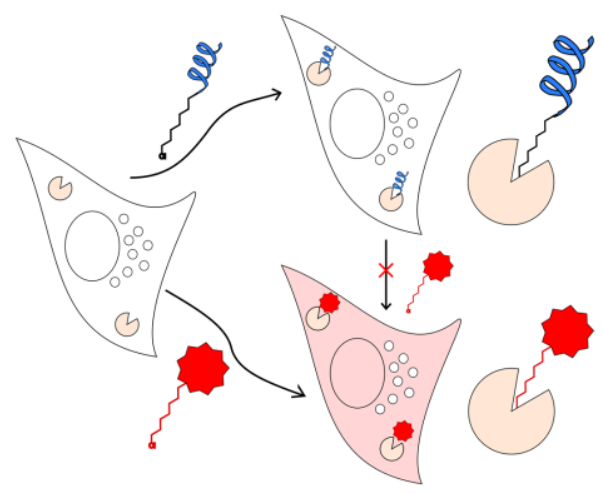

CAPA

Figure 3. Protein-based methods for the study of endosomal escape. a) Redistribution of proteins with defined cellular locations. b) Expression of a reporter gene after Cre recombinase delivery. An example of a construct is shown below. Cre recombinase removes a sequence between the promoter $(\mathrm{P})$ and the reporter gene (GFP) that blocked translation of the latter. c) Bimolecular fluorescence complementation (BiFC). Cells express an incomplete GFP protein, which fluorescence is reconstituted after the missing fragment, fused to other protein or peptide, reaches the cytosol. d) Glucocorticoid induced GFP translocation (GIGT) assay. GR-GFP fusion protein is in the cytosol until it binds dexamethasone, used as a tag in the molecule of interest, which prompts NLS exposure and nuclear accumulation. This is quantified by measuring GFP intensity of the nucleus and the surrounding cytosolic area (red circle). e) Chloroalkane penetration assay (CAPA) uses cells expressing HaloTag. Blocking HaloTag active site with a chloroalkane tag attached to the molecule of interest (top, blue) prevents the attachment of a fluorescent ligand (bottom, red), and the reduction of fluorescence is proportional to the endosomal release of the compound. 
NOTICE: This is the Accepted Version of the following article: Méndez Ardoy, A., Lostalé-Seijo, I., \& Montenegro, J. (2018). Where in the cell is our cargo? Current methods to study intracellular cytosolic localization. Chembiochem. doi: 10.1002/cbic.201800390 (C) 2018 WILEY-VCH Verlag GmbH \& Co. KGaA, Weinheim MINIREVIEW

and to compare the relative rates and mechanisms of endosomal escape of a particular molecular carrier. ${ }^{[6,78,103,104]}$

\subsection{Protein tagging}

CAPA (ChloroAlkane Penetration Assay) is based on the chloroalkane and haloenzyme (HaloTag) protein labelling system (Figure 3e). ${ }^{[71,72]}$ In this assay, the molecule of interest is labelled with a chloroalkane that can bind covalently to the active site of the enzyme, and incubated with a cell line that expresses the haloenzyme in the cytosol. The free amount of haloenzyme is then quantified by adding a cell permeable chloroalkane labelled fluorophore. The reduction of fluorescence compared with the control experiments of untreated cells is measured with a flow cytometer and it is proportional to the amount of cytosolic compound. ${ }^{[71,72]}$

\section{Others}

Although not easily accessible to all the chemical-biology groups interested in cell delivery, the recently developed state-of-the-art microscopy techniques are able to image fluorescent probes in living cells at a resolution in the range of tens of nanometers. ${ }^{[105]}$ This can be achieved by a range of techniques that have emerged in the last 20 years, such as stimulated emission depletion microscopy (STED) or stochastic optical reconstruction microscopy (STORM). ${ }^{[105]}$ Improvements of spatial resolution can be achieved by minimal modification of commercial equipment by using DNA-origami technologies. ${ }^{[106]}$ Combined with the development of specific probes, exceptional resolution of cell organelles in both fixed and live cells can be achieved ${ }^{[107]}$ and provide highly detailed information of localization and dynamic patterns for processes such as signal triggering. ${ }^{[108]}$ This unprecedented high resolution allows to study in higher detail the cellular distribution of common delivery systems, such as nanoparticles, both in bulk ${ }^{[109,110]}$ or after cell translocation. For example, agglomeration of silica nanoparticles in A549 cells has been studied by STED microscopy. ${ }^{[111]}$ Remarkably, quantitative information about aggregate sizes could be obtained revealing different aggregate size distribution as function of the incubation time. STED suitable probes can be used as cargos for selective visualization of organelles. In this sense, ruthenium polypyridyl complexes have been conjugated with targeted and non-targeted peptide sequences (nuclear localizing sequences, endoplasmic reticulum directing sequences, or non-targeted octaarginine sequences), thus allowing high resolution imaging of the endoplasmatic reticulum and the cell nucleus. ${ }^{[12]}$

Another technique for high resolution studies is correlative light and electron microscopy (CLEM), ${ }^{[113]}$ in which samples of live cells are examined by fluorescence microscopy and then processed for electron microscopy ${ }^{[113]}$ The development of the technique and related equipment has provided the possibility of acquiring both images almost simultaneously in a new generation of integrated CLEM microscopes. This excellent combination of techniques allows the study of the environment of the region of interest of the fluorescent label with an unprecedented high-resolution. Dense nanoparticles, the oxidation of diaminobenzidine by enzymes, or singlet-oxygen generated by some fluorophores and fluorescent proteins before osmium staining can be used to help in the alignment of the images. ${ }^{[13]}$ This technique, has been used to characterize the membrane-ruffling observed by arginine rich peptides at the surface of the cell during the endocytic uptake. ${ }^{[23]}$ Other specialized microscopy techniques that can be used to image gold nanoparticles include imaging methods such as SERS, photothermal microscopy, SNOM, ${ }^{[114]}$ hyperspectral[115] and dark field microscopy. ${ }^{[16]}$ These methods allow, in some cases, the distinction between free and vesicle-entrapped nanoparticles. ${ }^{[16]}$ There are other strategies for the study of distribution of compounds after incubation with cells. For instance, a method to follow the fate of cell-penetrating peptides relies on the modification of the non-internalized peptide with diazotized 2nitroaniline, which allows the quantification of the internalized, membrane associated and degraded peptide by HPLC. ${ }^{[17]}$ Protocols of subcellular fractionation, in which extracts containing cytosolic, vesicular or nuclear fractions of cells can be obtained with a careful selection of lysis buffers and centrifugation steps, have also been used for the study of the subcellular distribution of peptides, ${ }^{[118,119]}$ or peptide-protein conjugates. ${ }^{[73,120]}$ However, these two strategies cannot be applied in live cells and, especially the fractionation protocols, are time consuming and hard to implement for screening purposes.

\section{Conclusions and outlook}

As shown in this paper, chemists and biochemists interested in understanding the delivery processes can currently apply a broad toolbox for the study of the intracellular localization of molecules. In particular, demonstrating cytosolic delivery of cargos is of great interest for the development of next generation of therapeutics (nucleic acids, proteins, antibodies, etc.). However, each reporting technique has its pitfalls that should be carefully considered. The choice of the best method of analysis will depend on the particular application and technology available. Co-localization with fluorescent markers can be employed to distinguish the presence of molecules in the lysosome and other organelles. However, the precise tracking of early endosome could be more challenging and endosomal proteins and $\mathrm{pH}$ sensitive probes are required to differentiate the different stages of the endocytic pathway. The disulfide bond coupled to self-immolative linkers has been proven an excellent and orthogonal strategy to study the cytosol delivery of different molecules. However, one should keep in mind that it requires chemical modifications on the cargo and it can be sensitive to extracellular thiols. Microscopic analysis has significantly advanced in the last years with the appearance of spinning-disk confocal suitable for long-term live imaging, novel superresolution techniques and better fluorescent probes. However, the fluorophore and its intrinsic properties (quantum yield, photobleaching, $\mathrm{pK}_{\mathrm{a}}$, etc.) continue to be the major limitation in 
NOTICE: This is the Accepted Version of the following article: Méndez Ardoy, A., Lostalé-Seijo, I., \& Montenegro, J. (2018). Where in the cell is our cargo? Current methods to study intracellular cytosolic localization. Chembiochem. doi: 10.1002/cbic.201800390 (c) 2018 WILEY-VCH Verlag GmbH \& Co. KGaA, Weinheim

all these techniques. Additionally, the development of $\mathrm{pH}$ sensitive probes that can be excited in the near infrared opens the possibility of studying $\mathrm{pH}$ variations in tissues or in vivo. Other techniques relying on the delivery of an active cargo or the attachment of a tag sometimes present the problem of tag interference or the requirement of special cells for the analysis, which would require the preparation of modified cell lines for each cell type. Additionally, model proteins present strong differences in structure and stability and demonstrating delivery of the resistant saporin, does not guarantee that the delivery of other labile proteins, such as Caspase 3 , will work. It is therefore critical that chemists and biochemists will continue the work towards new creative solutions for optimized fluorescent probes, sensitive chemical motifs and new protein based strategies that can be employed to report on different intracellular localizations. Furthermore, the intrinsic interdisciplinary nature of the field, compulsory requires the joint efforts from chemistry and biology to identify different chemical and biological signals that can be exploited to improve spatiotemporal and orthogonal responses of the next generation of probes and methodologies.

\section{Acknowledgements}

We acknowledge funding from the Spanish Agencia Estatal de Investigación (AEI) [CTQ2014-59646-R, SAF2017-89890-R], the Xunta de Galicia (ED431G/09, ED431C 2017/25 and 2016AD031) and the ERDF. A. M.-A. received a MCIF from the EC (GLYCONANOPEP-750248). J. M. received a Ramón y Cajal (RYC-2013-13784), an ERC Starting Investigator Grant (DYNAP-677786) and a Young Investigator Grant from the Human Frontier Science Research Program (RGY0066/2017).

Keywords: Proteins $•$ Drug delivery $・$ Fluorophores $•$ Microscopy - Cells

[1] B. Leader, Q. J. Baca, D. E. Golan, Nat. Rev. Drug Discov. 2008, 7, 21-39.

H. Yin, K. J. Kauffman, D. G. Anderson, Nat. Rev. Drug Discov. 2017, 1-13.

[3] A. Fuertes, M. Juanes, J. R. Granja, J. Montenegro, Chem. Commun. 2017, 53, 7861-7871.

[4] J. M. Priegue, D. N. Crisan, J. Martínez-Costas, J. R. Granja, F. Fernandez-Trillo, J. Montenegro, Angew. Chemie - Int. Ed. 2016, 55, 7492-7495.

[5] J. M. Priegue, I. Lostalé-Seijo, D. Crisan, J. R. Granja, F. Fernández-Trillo, J. Montenegro, Biomacromolecules 2018, 19, 2638-2649.

[6] I. Lostalé-Seijo, I. Louzao, M. Juanes, J. Montenegro, Chem. Sci. 2017, 8, 7923-7931.

[7] L. Peraro, J. Kritzer, Angew. Chem. - Int. Ed. 2018, I, DOI 10.1002/ange.201801361

[8] J. P. Richard, K. Melikov, E. Vives, C. Ramos, B. Verbeure, M. J. Gait, L. V Chernomordik, B. Lebleu, J. Biol. Chem. 2003, 278, 585590.
[9] M. Lundberg, M. Johansson, Biochem. Biophys. Res. Commun. 2002, 291, 367-371.

[10] R. Fischer, K. Köhler, M. Fotin-Mleczek, R. Brock, J. Biol. Chem. 2004, 279, 12625-12635.

[11] J.-M. Swiecicki, F. Thiebaut, M. Di Pisa, S. Gourdin -Bertin, J. Tailhades, C. Mansuy, F. Burlina, S. Chwetzoff, G. Trugnan, G. Chassaing, et al., Sci. Rep. 2016, 6, 20237.

[12] L. D. Hughes, R. J. Rawle, S. G. Boxer, PLoS One 2014, 9, e87649.

[13] T. Cañeque, S. Müller, R. Rodriguez, Nat. Rev. Chem. 2018, DOI 10.1038/s41570-018-0030-x.

[14] N. Muthukrishnan, G. A. Johnson, A. Erazo-Oliveras, J. P. Pellois, Photochem. Photobiol. 2013, 89, 625-630.

[15] S. BOLTE, F. P. CORDELIÈRES, J. Microsc. 2006, 224, 213-232.

[16] H. Zhu, J. Fan, J. Du, X. Peng, Acc. Chem. Res. 2016, 49, 21152126.

[17] J. Zielonka, J. Joseph, A. Sikora, M. Hardy, O. Ouari, J. VasquezVivar, G. Cheng, M. Lopez, B. Kalyanaraman, Chem. Rev. 2017, 117, 10043-10120

[18] J. A. Kilgore, N. J. Dolman, M. W. Davidson, in Curr. Protoc. Cytom., John Wiley \& Sons, Inc., Hoboken, NJ, USA, 2014, p. 12.32.112.32.17.

[19] J. A. Kilgore, N. J. Dolman, M. W. Davidson, in Curr. Protoc. Cytom., John Wiley \& Sons, Inc., Hoboken, NJ, USA, 2013, p. 12.31.112.31.24.

[20] N. J. Dolman, J. A. Kilgore, M. W. Davidson, in Curr. Protoc. Cytom., John Wiley \& Sons, Inc., Hoboken, NJ, USA, 2013, p. 12.30.112.30.27.

[21] I. Johnson, M. Spence, Molecular Probes Handbook: A Guide to Fluorescent Probes and Labeling Technologies, Life Technologies Corp, USA, 2010, 2010.

[22] J. A. Swanson, B. D. Yirinec, S. C. Silverstein, J. Cell Biol. 1985, 100, 851-859.

[23] H. Hirose, T. Takeuchi, H. Osakada, S. Pujals, S. Katayama, I. Nakase, S. Kobayashi, T. Haraguchi, S. Futaki, Mol. Ther. 2012, 20 , 984-993.

[24] G. J. Doherty, H. T. McMahon, Annu. Rev. Biochem. 2009, 78, 857902.

[25] A. Wandinger-Ness, M. Zerial, Cold Spring Harb. Perspect. Biol. 2014, 6, a022616.

[26] J. Huotari, A. Helenius, EMBO J. 2011, 30, 3481-500.

[27] P. G. Canonico, J. W. Bird, J. Cell Biol. 1969, 43, 367-371.

[28] E. C. Freundt, M. Czapiga, M. J. Lenardo, Cell Res. 2007, 17, 956958.

[29] F. Fan, S. Nie, D. Yang, M. Luo, H. Shi, Y. H. Zhang, Bioconjug. Chem. 2012, 23, 1309-1317.

[30] J. M. Falcon-Perez, J. Cell Sci. 2005, 118, 5243-5255.

[31] C. T. Rueden, J. Schindelin, M. C. Hiner, B. E. DeZonia, A. E. Walter, E. T. Arena, K. W. Eliceiri, BMC Bioinformatics 2017, 18, 529.

[32] J. S. Aaron, A. B. Taylor, T.-L. Chew, J. Cell Sci. 2018, 131, jcs211847.

[33] J. R. Casey, S. Grinstein, J. Orlowski, Nat. Rev. Mol. Cell Biol. 2010, $11,50-61$.

[34] Y. Wang, C. Wang, Y. Li, G. Huang, T. Zhao, X. Ma, Z. Wang, B. D. 
NOTICE: This is the Accepted Version of the following article: Méndez Ardoy, A., Lostalé-Seijo, I., \& Montenegro, J. (2018). Where in the cell is our cargo? Current methods to study intracellular cytosolic localization. Chembiochem. doi: 10.1002/cbic.201800390 (c) 2018 WILEY-VCH Verlag GmbH \& Co. KGaA, Weinheim

Sumer, M. A. White, J. Gao, Adv. Mater. 2017, 29, 1603794.

E. Nakata, Y. Nazumi, Y. Yukimachi, Y. Uto, H. Maezawa, T. Hashimoto, Y. Okamoto, H. Hori, Bioorg. Med. Chem. Lett. 2011, 21, 1663-1666.

[36] J. Liu, Z. Diwu, W.-Y. Leung, Bioorg. Med. Chem. Lett. 2001, 11, 2903-2905.

[37] Y. Yue, F. Huo, S. Lee, C. Yin, J. Yoon, Analyst 2017, 142, 30-41.

[38] M. Schäferling, Wiley Interdiscip. Rev. Nanomedicine Nanobiotechnology 2016, 8, 378-413.

[39] Q. Wan, S. Chen, W. Shi, L. Li, H. Ma, Angew. Chemie - Int. Ed. 2014, 53, 10916-10920.

[40] Z. Xue, H. Zhao, J. Liu, J. Han, S. Han, ACS Sensors 2017, 2, 436442.

[41] S. Takahashi, Y. Kagami, K. Hanaoka, T. Terai, T. Komatsu, T. Ueno, M. Uchiyama, I. Koyama-Honda, N. Mizushima, T. Taguchi, et al., J. Am. Chem. Soc. 2018, 140, 5925-5933.

[42] J. Mei, N. L. C. Leung, R. T. K. Kwok, J. W. Y. Lam, B. Z. Tang, Chem. Rev. 2015, 115, 11718-11940.

[43] S. Chen, Y. Hong, Y. Liu, J. Liu, C. W. T. Leung, M. Li, R. T. K. Kwok, E. Zhao, J. W. Y. Lam, Y. Yu, et al., J. Am. Chem. Soc. 2013, 135, 4926-4929.

[44] Z. Yang, W. Qin, J. W. Y. Lam, S. Chen, H. H. Y. Sung, I. D. Williams, B. Z. Tang, Chem. Sci. 2013, 4, 3725-3730.

[45] K. Li, Q. Feng, G. Niu, W. Zhang, Y. Li, M. Kang, K. Xu, J. He, H. Hou, B. Z. Tang, ACS Sensors 2018, 3, 920-928.

[46] J. Wang, S. Xia, J. Bi, M. Fang, W. Mazi, Y. Zhang, N. Conner, F.-T. [71] Luo, H. P. Lu, H. Liu, Bioconjug. Chem. 2018, 29, 1406-1418.

[47] Z. Wang, C. Gui, E. Zhao, J. Wang, X. Li, A. Qin, Z. Zhao, Z. Yu, B. Z. Tang, ACS Appl. Mater. Interfaces 2016, 8, 10193-10200.

[48] F. Helmchen, W. Denk, Nat. Methods 2005, 2, 932-940.

[49] H. M. Kim, M. J. An, J. H. Hong, B. H. Jeong, O. Kwon, J.-Y. Hyon, S.-C. Hong, K. J. Lee, B. R. Cho, Angew. Chemie - Int. Ed. 2008, 47, 2231-2234.

[50] H. J. Kim, C. H. Heo, H. M. Kim, J. Am. Chem. Soc. 2013, 135, 17969-17977.

[51] A. R. Sarkar, C. H. Heo, L. Xu, H. W. Lee, H. Y. Si, J. W. Byun, H. M. Kim, Chem. Sci. 2016, 7, 766-773.

[52] Y. Wei, D. Cheng, T. Ren, Y. Li, Z. Zeng, L. Yuan, Anal. Chem. 2016, 88, 1842-1849.

[53] Z. Qian, P. G. Dougherty, D. Pei, Chem. Commun. 2015, 51, 21622165.

[54] R. P. Kulkarni, S. Mishra, S. E. Fraser, M. E. Davis, Bioconjug. Chem. 2005, 16, 986-994.

[55] A. Akinc, R. S. Langer, Biotechnol. Bioeng. 2002, 78, 503-508.

[56] J. Hu, G. Liu, C. Wang, T. Liu, G. Zhang, S. Liu, Biomacromolecules 2014, 15, 4293-4301.

[57] N. M. Moore, C. L. Sheppard, T. R. Barbour, S. E. Sakiyama-Elbert, J. Gene Med. 2008, 10, 1134-49.

[58] M. Hällbrink, A. Florén, A. Elmquist, M. Pooga, T. Bartfai, Ü. Langel, Biochim. Biophys. Acta - Biomembr. 2001, 1515, 101-109.

[59] A. Brezden, M. F. Mohamed, M. Nepal, J. S. Harwood, J. Kuriakose, M. N. Seleem, J. Chmielewski, J. Am. Chem. Soc. 2016, 138, 10945-10949.
[61]

L. H. Rome, P. A. Wender, ACS Nano 2017, 11, 872-881.

A. Wender, J. Am. Chem. Soc. 2006, 128, 6526-6527.

[62] C. Batisse, E. Dransart, R. Ait Sarkouh, L. Brulle, S.-K. Bai, S. Godefroy, L. Johannes, F. Schmidt, Eur. J. Med. Chem. 2015, 95, 483-491.

[63] J. Xu, J. Wang, J. C. Luft, S. Tian, G. Owens, A. A. Pandya, P. Berglund, P. Pohlhaus, B. W. Maynor, J. Smith, et al., J. Am. Chem. Soc. 2012, 134, 8774-8777.

[64] E. A. Dubikovskaya, S. H. Thorne, T. H. Pillow, C. H. Contag, P. A. Wender, Proc. Natl. Acad. Sci. 2008, 105, 12128-12133.

[65] S. Bhuniya, S. Maiti, E.-J. Kim, H. Lee, J. L. Sessler, K. S. Hong, J. S. Kim, Angew. Chemie - Int. Ed. 2014, 53, 4469-4474.

[66] X. Hu, G. Liu, Y. Li, X. Wang, S. Liu, J. Am. Chem. Soc. 2015, 137, 362-368.

[67] L. Brülisauer, N. Kathriner, M. Prenrecaj, M. A. Gauthier, J.-C. Leroux, Angew. Chemie - Int. Ed. 2012, 51, 12454-12458.

[68] E. Eiríksdóttir, I. Mäger, T. Lehto, S. El Andaloussi, U. Langel, Bioconjug. Chem. 2010, 21, 1662-1672.

[69] T. H. Pillow, J. D. Sadowsky, D. Zhang, S.-F. Yu, G. Del Rosario, K. Xu, J. He, S. Bhakta, R. Ohri, K. R. Kozak, et al., Chem. Sci. 2017, 8, 366-370.

[70] J. S. Kim, D. K. Choi, S. W. Park, S. M. Shin, J. Bae, D. M. Kim, T. H. Yoo, Y. S. Kim, Biochem. Biophys. Res. Commun. 2015, 467, 771-777.

L. Peraro, Z. Zou, K. M. Makwana, A. E. Cummings, H. L. Ball, H. Yu, Y. S. Lin, B. Levine, J. a A. Kritzer, J. Am. Chem. Soc. 2017, 139, 7792-7802.

[72] L. Peraro, K. L. Deprey, M. K. Moser, Z. Zou, H. L. Ball, B. Levine, J. A. Kritzer, J. Am. Chem. Soc. 2018, jacs.8b06144.

[73] M. Li, Y. Tao, Y. Shu, J. R. LaRochelle, A. Steinauer, D. Thompson, A. Schepartz, Z.-Y. Y. Chen, D. R. Liu, J. Am. Chem. Soc. 2015, 137, 14084-14093.

[74] W. P. R. Verdurmen, M. Mazlami, A. Plückthun, Sci. Rep. 2017, 7, 13194.

[75] T.-Y. Chao, R. T. Raines, Mol. Biosyst. 2013, 9, 339-342.

[76] S. Schmidt, M. J. W. Adjobo-Hermans, R. Wallbrecher, W. P. R. Verdurmen, P. H. M. Bovée-Geurts, J. Van Oostrum, F. Milletti, T. Enderle, R. Brock, Angew. Chemie - Int. Ed. 2015, 54, 1510515108.

[77] N. Milech, B. A. Longville, P. T. Cunningham, M. N. Scobie, H. M. Bogdawa, S. Winslow, M. Anastasas, T. Connor, F. Ong, S. R. Stone, et al., Sci. Rep. 2016, 5, 18329.

[78] J. M. Holub, J. R. Larochelle, J. S. Appelbaum, A. Schepartz, Biochemistry 2013, 52, 9036-9046.

[79] K. A. Mix, J. E. Lomax, R. T. Raines, J. Am. Chem. Soc. 2017, 139, 14396-14398.

[80] M. C. Morris, J. Depollier, J. Mery, F. Heitz, G. Divita, Nat. Biotechnol. 2001, 19, 1173-6.

[81] A. L. J. Marschall, C. Zhang, S. Dübel, in Cancer Gene Networks, 2017, pp. 201-208.

[82] M. Akishiba, T. Takeuchi, Y. Kawaguchi, K. Sakamoto, H.-H. Yu, I. Nakase, T. Takatani-Nakase, F. Madani, A. Gräslund, S. Futaki, Nat. Chem. 2017, 9, 751-761. 
NOTICE: This is the Accepted Version of the following article: Méndez Ardoy, A., Lostalé-Seijo, I., \& Montenegro, J. (2018). Where in the cell is our cargo? Current methods to study intracellular cytosolic localization. Chembiochem. doi: 10.1002/cbic.201800390 (c) 2018 WILEY-VCH Verlag GmbH \& Co. KGaA, Weinheim

H. D. Herce, D. Schumacher, A. F. L. Schneider, A. K. Ludwig, F. A. Mann, M. Fillies, M.-A. Kasper, S. Reinke, E. Krause, H. Leonhardt, et al., Nat. Chem. 2017, 9, 762-771.

[84] L. I. Selby, C. M. Cortez-Jugo, G. K. Such, A. P. R. Johnston, Wiley Interdiscip. Rev. Nanomedicine Nanobiotechnology 2017, 9, e1452.

[85] T. Gaj, J. Liu, K. E. Anderson, S. J. Sirk, C. F. Barbas, ACS Chem. Biol. 2014, 9, 1662-1667.

[86] G. Meinke, A. Bohm, J. Hauber, M. T. Pisabarro, F. Buchholz, Chem. Rev. 2016, 116, 12785-12820.

[87] J. J. Cronican, D. B. Thompson, K. T. Beier, B. R. McNaughton, C. L. Cepko, D. R. Liu, ACS Chem. Biol. 2010, 5, 747-752.

[88] J. A. Zuris, D. B. Thompson, Y. Shu, J. P. Guilinger, J. L. Bessen, J. H. Hu, M. L. Maeder, J. K. Joung, Z.-Y. Chen, D. R. Liu, Nat. Biotechnol. 2014, 33, 73-80.

[89] M. Wang, J. A. Zuris, F. Meng, H. Rees, S. Sun, P. Deng, Y. Han, X. Gao, D. Pouli, Q. Wu, et al., Proc. Natl. Acad. Sci. U. S. A. 2016, 113, 2868-73.

D. S. D'Astolfo, R. J. Pagliero, A. Pras, W. R. Karthaus, H. Clevers, V. Prasad, R. J. Lebbink, H. Rehmann, N. Geijsen, Cell 2015, 161, 674-690.

[91] A. L. J. Marschall, C. Zhang, A. Frenzel, T. Schirrmann, M. Hust, F. Perez, S. Dübel, MAbs 2014, 6, 943-956.

[92] M. Howarth, A. Y. Ting, Nat. Protoc. 2008, 3, 534-545. W. P. R. Verdurmen, M. Luginbühl, A. Honegger, A. Plückthun, J. Control. Release 2015, 200, 13-22.

A. Varshavsky, Methods Enzymol. 2005, 399, 777-99.

F. Loison, P. Nizard, T. Sourisseau, P. Le Goff, L. Debure, Y. Le Drean, D. Michel, Mol. Ther. 2005, 11, 205-214.

V. Postupalenko, D. Desplancq, I. Orlov, Y. Arntz, D. Spehner, Y. Mely, B. P. Klaholz, P. Schultz, E. Weiss, G. Zuber, Angew. Chemie - Int. Ed. 2015, 54, 10583-10586.

J. E. Dixon, G. Osman, G. E. Morris, H. Markides, M. Rotherham, Z. Bayoussef, A. J. El Haj, C. Denning, K. M. Shakesheff, Proc. Natl. Acad. Sci. U. S. A. 2016, 113, E291-E299.

[98] T. K. Kerppola, Annu. Rev. Biophys. 2008, 37, 465-487.

[99] S. Cabantous, T. C. Terwilliger, G. S. Waldo, Nat. Biotechnol. 2005, 23, 102-107

[100] S.-M. Shin, D.-K. Choi, K. Jung, J. Bae, J. Kim, S. Park, K.-H. Song, Y.-S. Kim, Nat. Commun. 2017, 8, 15090.

[101] S. H. Medina, S. E. Miller, A. I. Keim, A. P. Gorka, M. J. Schnermann, J. P. Schneider, Angew. Chemie - Int. Ed. 2016, 55, 3369-3372.
[102] Y. U. Kwon, T. Kodadek, J Am Chem Soc 2007, 129, 1508-1509.

[103] D. S. Daniels, A. Schepartz, J. Am. Chem. Soc. 2007, 129, 1457814579.

[104] M. Juanes, I. Lostalé-Seijo, J. R. Granja, J. Montenegro, Chem. - A Eur. J. 2018, DOI 10.1002/chem.201800706.

[105] S. Cox, Dev. Biol. 2015, 401, 175-181.

[106] F. Schueder, J. Lara-Gutiérrez, B. J. Beliveau, S. K. Saka, H. M. Sasaki, J. B. Woehrstein, M. T. Strauss, H. Grabmayr, P. Yin, R. Jungmann, Nat. Commun. 2017, 8, 2090.

[107] S. Sreedharan, M. R. Gill, E. Garcia, H. K. Saeed, D. Robinson, A. Byrne, A. Cadby, T. E. Keyes, C. Smythe, P. Pellett, et al., J. Am. Chem. Soc. 2017, 139, 15907-15913.

[108] S. J. L. van Wijk, F. Fricke, L. Herhaus, J. Gupta, K. Hötte, F. Pampaloni, P. Grumati, M. Kaulich, Y. Sou, M. Komatsu, et al., Nat. Microbiol. 2017, 2, 17066.

[109] Y. Tahara, S. Mukai, S. Sawada, Y. Sasaki, K. Akiyoshi, Adv. Mater. 2015, 27, 5080-5088.

[110] N. Prabhakar, T. Näreoja, E. von Haartman, D. Ş. Karaman, H. Jiang, S. Koho, T. A. Dolenko, P. E. Hänninen, D. I. Vlasov, V. G. Ralchenko, et al., Nanoscale 2013, 5, 3713.

[111] S. Schübbe, C. Cavelius, C. Schumann, M. Koch, A. Kraegeloh, Adv. Eng. Mater. 2010, 12, 417-422.

[112] A. Byrne, C. S. Burke, T. E. Keyes, Chem. Sci. 2016, 7, 6551-6562.

[113] P. De Boer, J. P. Hoogenboom, B. N. G. Giepmans, Nat. Methods 2015, 12, 503-513.

[114] M. D'Acunto, Materials (Basel). 2018, 11, 882.

[115] S. Patskovsky, E. Bergeron, M. Meunier, J. Biophotonics 2015, 8, 162-167.

[116] S.-H. Wang, C.-W. Lee, A. Chiou, P.-K. Wei, J. Nanobiotechnology 2010, 8, 33.

[117] T. Holm, H. Johansson, P. Lundberg, M. Pooga, M. Lindgren, Ü. Langel, Nat. Protoc. 2006, 1, 1001-1005.

[118] H. Räägel, P. Säl̈lik, M. Hansen, Ü. Langel, M. Pooga, J. Control. Release 2009, 139, 108-117.

[119] J. L. Zaro, W. C. Shen, Biochem. Biophys. Res. Commun. 2003, 307, 241-247.

[120] R. Kenien, W. C. Shen, J. L. Zaro, J. Drug Target. 2012, 20, 793800 . 
NOTICE: This is the Accepted Version of the following article: Méndez Ardoy, A., Lostalé-Seijo, I., \& Montenegro, J. (2018). Where in the cell is our cargo? Current methods to study intracellular cytosolic localization. Chembiochem. doi: 10.1002/cbic.201800390 (C) 2018 WILEY-VCH Verlag GmbH \& Co. KGaA, Weinheim

Entry for the Table of Contents (Please choose one layout)

Layout 1:

\section{MINIREVIEW}

Delivery of active substances into the cytosol face several barriers. Methods for the study of subcellular location are essential to understand the limitations of carriers, and improve their characteristics. A summary of the strategies that can be used to confirm cytosolic delivery and subcellular localization is described in this review.

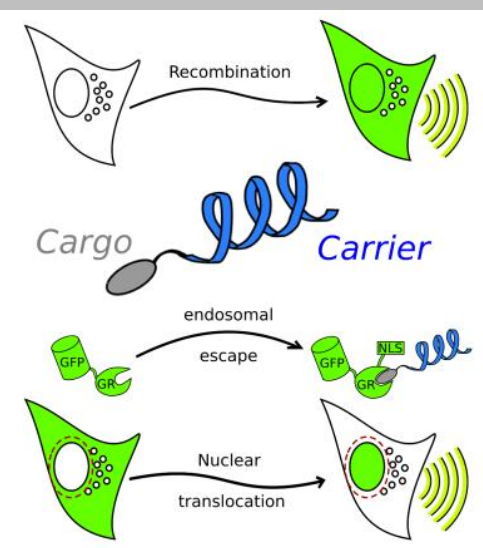

Alejandro Méndez-Ardoy, Irene Lostalé-Seijo, Javier Montenegro*

Page No. - Page No.

Where in the cell is our cargo? Current methods to study intracellular cytosolic localization.

Layout 2:

MINIREVIEW

((Insert TOC Graphic here))

Text for Table of Contents
Author(s), Corresponding Author(s)*

Page No. - Page No.

Title 